\title{
The Role of Housework in Married Women's Physical Activity: 1936 to 2017
}

\author{
Cathleen D. Zick* \\ Department of Family and Consumer Studies, University of Utah, Salt Lake City, Utah, United States of America \\ *Corresponding author: zick@fcs.utah.edu
}

Received April 07, 2019; Revised May 22, 2019; Accepted June 15, 2019

\begin{abstract}
The historical decline in adults' physical activity (PA) has been attributed to the growth in both sedentary occupations and car-dependent transportation. Missing from the conversation has been any examination of what role shifts in housework time/composition may have played. Historical time-use data for married women in the United States from 1936 to 2017 are used to assess trends in women's moderate physical activity (PA) housework as measured by the typical metabolic equivalents (METs) for various core housework tasks. Analyses reveal that for much of the 20th century, the typical married woman likely met the Centers for Disease Control's PA recommendations through daily housework. However, time spent in moderate PA housework has declined at a faster pace than total housework time for the past 30 years. The downward trend appears to be driven primarily by changes other than household socio-demographics. Shifts in housework, both in terms of the composition and the overall time spent doing housework, have likely played an important role in the historical decline of adult women's physical activity and rising obesity risk.
\end{abstract}

Keywords: women and housework, moderate physical activity, historical trends

Cite This Article: Cathleen D. Zick, "The Role of Housework in Married Women's Physical Activity: 1936 to 2017." Journal of Physical Activity Research, vol. 4, no. 2 (2019): 97-102. doi: 10.12691/jpar-4-2-3.

\section{Introduction}

American adults are less physically active today than they were 40 years ago $[1,2,3]$ and this decline in physical activity (PA) is associated with increased risk of mortality and morbidity $[4,5,6]$. The downward trend in adults' PA has been attributed to the growth in both sedentary occupations and car-dependent transportation. As America shifted from a manufacturing to a service economy, PA-related occupational demands declined. In addition, as growing numbers of Americans moved from cities to the suburbs, they became more car-dependent for their transportation needs [1]. Taken together, these downward PA pressures have swamped the modest gains Americans have made in leisure-related PA over the past $40+$ years $[3,7]$.

Missing from the PA conversation has been any detailed examination of what role, if any, shifts in housework time and composition may have played in Americans' declining PA despite the fact that housework consumes a significant portion of women's time [1]. Indeed, a review of the early time use studies reveals that total housework averaged between 47.1 and 58.6 hours per week in the 1920s and 1930s [8]. However, by 2015, the typical amount of time devoted to housework by all women had declined to 15.75 hours per week [9]. At the same time, the composition of married women's housework changed as there were substantial declines in time spent in meal preparation and cleanup, textile construction and care, and home care while there were increases in time spent in shopping and managerial tasks [10,11].

What have the shifts in married women's housework implied for their PA? In this study, unique historical timeuse data are linked to information on the typical metabolic equivalents (METs) for various core housework tasks to assess trends in PA-related housework time from 1936 to 2017 for married American women. In the multivariate analyses, Blinder-Oaxaca decompositions [12] are used to tease out the relative role that changes in sociodemographics have played in women's shifting PA-related housework time.

\section{Materials and Methods}

\subsection{The Data}

Data for the analyses come from seven different American time-diary studies that span $80+$ years. Key elements of each survey are summarized in Table 1. These time-diary surveys differ in sample sizes, modes of delivery, seasonality of the interviews, and geographic coverage. Nevertheless, we elect to begin with a 1936 survey because of its relatively large sample size and because of its geographic and methodological comparability to the 1952 survey. That second survey provides a rare glimpse of married women's time use post-World War II 
and prior to the initiation of any national time use surveys. The 1965-66 survey was the first national time-diary survey, however, its sampling frame excluded rural households. Beginning with the 1975-76 survey and going forward, data from the time-diary surveys are nationally representative when weighted. The early surveys contain information about the presence/absence of household technology that could be associated with PA (e.g., electric versus wood-burning stoves). Unfortunately, such questions were not included in the later surveys.

Samples drawn from each survey for the descriptive analyses are restricted to married women, between the ages of 18 and 64, whose time diary was for a weekday. We make these restrictions in order to maximize comparability across time as in the earliest two surveys all time diary observations are for weekdays and only married women were interviewed. Furthermore, the 18-64 age restriction is consistent with the 1965-66 survey's more limited age range. For the multivariate analyses that utilize only the 1985 and 2007 data, the weekday restriction is relaxed.

\subsection{Linking Housework Diary Activities to Metabolic Equivalents (METs)}

The first step in linking housework diary activities to METs is to determine what core housework activities can be confidently equated across the surveys. The pre-defined housework activities measured in each survey that are comparable include upkeep of the home (i.e., cleaning), gardening, yard work, and pet care, sewing, mending and knitting, clothing care (i.e., washing and ironing), meal preparation and meal cleanup, and shopping. These "core housework" activities generally parallel the categories used in past historical research $[8,10,11,19]$.

The sub-categories of women's housework are joined to the typical intensity of the activity using the Compendium of Physical Activities [20,21], and the linkage protocol developed by Tudor-Locke, et al. [22]. The most recent government recommendations are that healthy adults engage in 150 minutes of moderate PA (i.e., activities generating 3.0-5.9 METs) or 75 minutes of vigorous PA (i.e., activities generating 6.0+ METs) per week, or an equivalent combination of the two [23]. Given these criteria, only time spent in "upkeep of the home" (e.g., cleaning, taking out the trash, making the beds) and "gardening, yard work, and pet care" meet the criteria of being moderate PA consistently across time.

In the 1936 and 1952 surveys, time spent doing laundry without the help of an automatic washing machine and hanging out clothes to air dry would have also been counted as moderate PA as the Compendium indicates that hand washing and hanging out clothes to dry is associated with 4.0 METs [20,21]. In the 1936 survey, 16 percent of the survey participants $(\mathrm{N}=65)$ reported washing clothes by hand and another 12 percent used a hand powered washing machine. None of the 406 women had a dryer and thus all hung out their clothes to dry. In the 1952 survey, 92 percent of the participants reported having an automatic washing machine but only 6 percent had a dryer, suggesting that the majority of women in the 1952 study still hung out clothes to dry. Thus, to the extent that these activities are omitted from moderate PA housework, the estimates for those two years are conservative.

\subsection{Analyses}

The analyses begin with a descriptive presentation of time spent in all core housework and housework involving moderate PA, across the $80+$ year period. Next, Tobit multivariate regressions are estimated for the 1985 and 2017 nationally representative surveys as those two years bracket the era when moderate PA housework began to no longer meet overall PA recommendations for the average married woman. Tobit estimation is used because time spent in moderate PA housework is censored at zero. Independent variables are confined to those sociodemographic measures that are consistently available across the surveys. The cutoff of 40 years is used for the age dichotomous variable because it approximates the age at which childbearing would no longer be confounding age effects. Similarly, education is dichotomized at $12+$ years in order to ascertain whether post-high school education effects alter women's opportunity costs of engaging in housework. Tests for age by education interactions were insignificant and thus omitted from the final estimating equation.

Table 1. Descriptions of Time-Diary Surveys

\begin{tabular}{|c|c|c|c|c|}
\hline Survey Name (Year) & Diary Days & $\begin{array}{c}\text { Geographic } \\
\text { Coverage }\end{array}$ & Sample Parameters & $\begin{array}{c}\text { Survey Mode } \\
\text { (Analysis N) }\end{array}$ \\
\hline $\begin{array}{c}\text { The Use of Time in Relation } \\
\text { to Home Management [13] } \\
\text { (1936) }\end{array}$ & $\begin{array}{l}\text { March to May / weekdays } \\
\text { only }\end{array}$ & $\begin{array}{l}\text { Farms in Genesee } \\
\text { County, NY }\end{array}$ & $\begin{array}{l}\text { Married women who were full-time } \\
\text { homemakers }\end{array}$ & $\begin{array}{l}\text { Personal Interviews } \\
\qquad(\mathrm{N}=406)\end{array}$ \\
\hline $\begin{array}{l}\text { Use of Time of Farm \& City } \\
\text { Full-Time Homemakers \& in } \\
\text { the Labor Force [14] (1952) }\end{array}$ & $\begin{array}{c}\text { March to June / weekdays } \\
\text { only }\end{array}$ & $\begin{array}{l}\text { Genesee County } \\
\text { and Auburn, NY }\end{array}$ & $\begin{array}{l}\text { Married women who were full-time } \\
\text { homemakers or employed }\end{array}$ & $\begin{array}{l}\text { Personal Interviews } \\
\qquad(\mathrm{N}=236)\end{array}$ \\
\hline $\begin{array}{c}\text { Americans' Use of Time, } \\
1965-66[15]\end{array}$ & $\begin{array}{l}\text { Nov. - Dec. } 1965 \text {; March to } \\
\text { April } 1966\end{array}$ & National sample & $\begin{array}{l}\text { Adults age 19-65 living in cities with } \\
30,000-280,000 \text { residents plus a sub- } \\
\text { sample of adults living in Jackson, MI }\end{array}$ & $\begin{array}{l}\text { Personal Interviews } \\
\& \text { self-enumeration } \\
(\mathrm{N}=612)\end{array}$ \\
\hline $\begin{array}{c}\text { Time Use in Economic and } \\
\text { Social Accounts [16] } \\
(1975-76) \\
\end{array}$ & Oct. - Nov. & $\begin{array}{c}\text { Nationally } \\
\text { representative } \\
\text { sample } \\
\end{array}$ & $\begin{array}{l}\text { Multistage area probability sampling of } \\
\text { households. }\end{array}$ & $\begin{array}{l}\text { Personal Interviews } \\
\text { (Wave 1) }(\mathrm{N}=704)\end{array}$ \\
\hline $\begin{array}{l}\text { Americans' Use of Time, } \\
1985[17]\end{array}$ & Jan. - Dec. & $\begin{array}{l}\text { Nationally } \\
\text { representative } \\
\text { sample }\end{array}$ & Adults age 18 and older & $\begin{array}{l}\text { Mail, telephone, \& } \\
\text { interviews } \\
(\mathrm{N}=1,264)\end{array}$ \\
\hline $\begin{array}{c}\text { American Time Use Survey } \\
{[18](2003,2017)}\end{array}$ & Jan. - Dec. & $\begin{array}{l}\text { Nationally } \\
\text { representative } \\
\text { sample }\end{array}$ & $\begin{array}{l}\text { Households are drawn from those that } \\
\text { have completed the final month of the } \\
\text { Current Population Survey. }\end{array}$ & $\begin{array}{c}\text { Telephone }(2003 \\
\mathrm{N}=5,140 ; 2017 \\
\mathrm{~N}=2,098)\end{array}$ \\
\hline
\end{tabular}


An Oaxaca-Blinder decomposition of moderate PA housework time is employed to assess what fraction in the overall change in time during the 1985 to 2017 period is attributable to changes in the socio-demographic characteristics of married women and what fraction may be attributable to shifts in elements that were not captured in the national surveys (e.g. the adoption of new labor-saving household technologies, the growth in market substitutes for housework, changes in cultural norms regarding housekeeping). Given the censored nature of the dependent variable, a modified Oaxaca-Blinder decomposition approach for nonlinear regressions is utilized to parse out the effects [24,25].

This study was deemed to be exempt by the university's institutional review board. All descriptive analyses and Tobit estimates utilize SAS 9.4 while the decomposition estimation is done utilizing Stata 13.0 so as to capitalize on its nonlinear Oaxaca-Blinder routine. Diagnostic multicollinearity tests run prior to estimating the equations reveal no areas of concern.

\section{Results}

Figure 1 shows median total core housework and core housework involving moderate PA in each of the survey years. The median housework time of approximately seven hours per day in 1936 (422 $\mathrm{min} . / 60 \mathrm{~min} / \mathrm{hr}$ ) mirrors other historical time-use reports [8,11,26,27]. In 1936, approximately $30 \%$ of that time (i.e., $129 \mathrm{~min} . / 422 \mathrm{~min}$.) was spent in housework that involved moderate PA.

The married women living on farms in Upstate New York, on average, were spending a little more than two hours per day in moderate PA housework, a figure that is four times the current CDC recommendation of 150 minutes of PA per week [23]. Similarly, the average married woman in the 1952 and 1965-66 samples also exceeded the CDC's PA recommendation simply by engaging in housework. While we cannot generalize from these early studies, collectively they paint a picture of moderate PA housework that involved sizeable absolute amounts and considerable relative shares (i.e., in the range of $16-30 \%$ ) of all housework activities.

Turning to nationally representative data from 1975-76 onward, the absolute amount of moderate PA housework time does not change, on average, between 1975-76 and 1985. However, it declines between 1985 and 2003 and between 2003 and 2017. The median time for married women engaging in moderate PA housework is just nine minutes per weekday in 2017, which by itself does not meet the CDC's recommendations for PA. While the absolute decline is marked over this period, the relative decline is even more striking, with only 8 percent of women's housework time spent in activities generating 3.0+ METs by 2017. Essentially, Figure 1 suggests that between 1985 and 2017, time spent in moderate PA housework declined at a faster rate than did core housework more generally. (Descriptive analyses that include weekend day diaries for 1975-76, 1985, 2003, and 2017, replicate these results and are available from the author upon request.) This observation is also consistent with the decline in the percentage of married women who report doing any moderate PA housework on the diary day. These percentages are relatively consistent between $1975-76$ and 1985 (i.e., $73.4 \%$ and $75.7 \%$ respectively) but decline substantially by 2017 when only $54.15 \%$ report doing any moderate PA housework on the diary day.

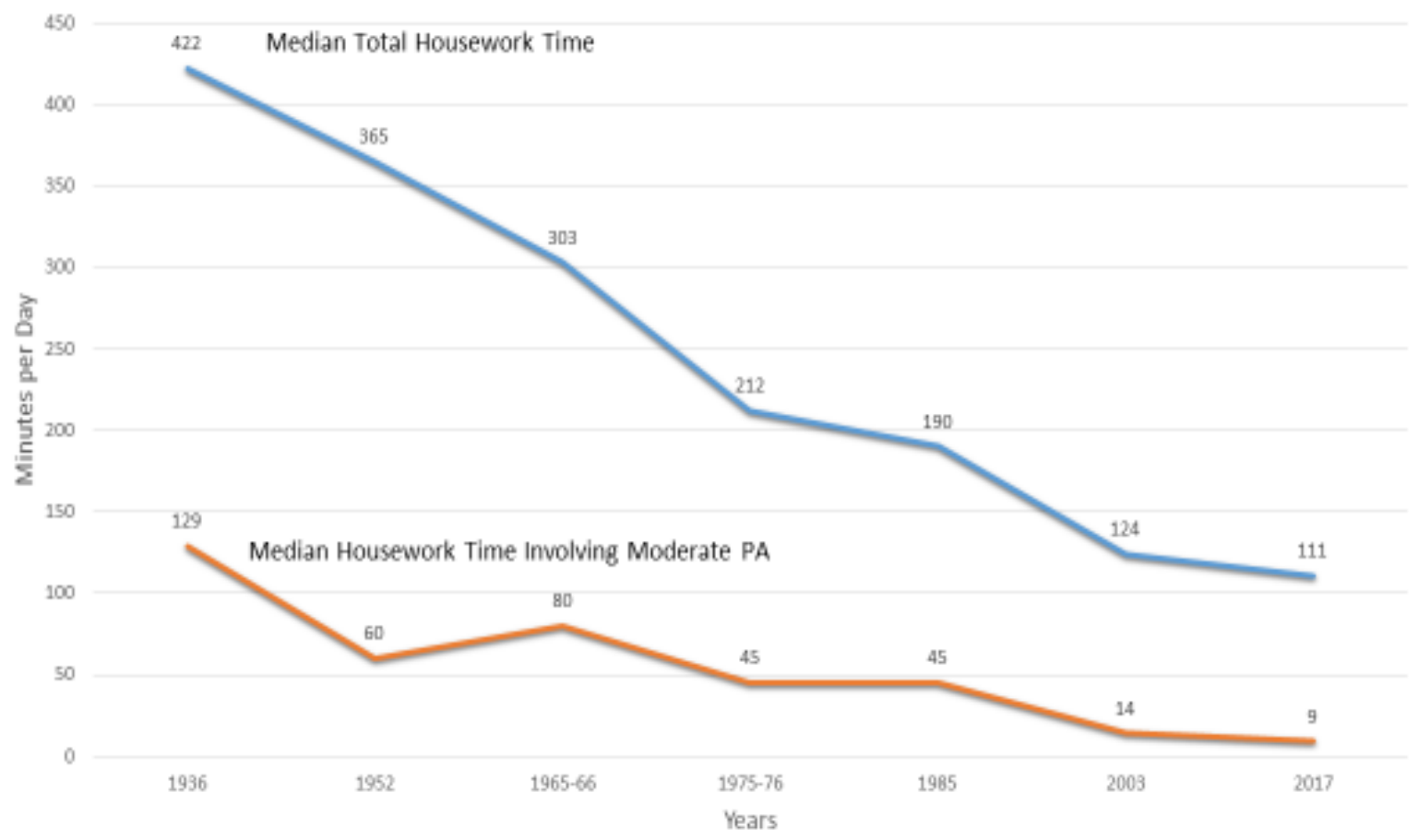

${ }^{3}$ For the purposes of the descriptive analyses, observations from the 1975-76, 1985, 2003, and 2017 surveys are restricted to those married women with weekday diaries only. As a consequence, their sample sizes for Fig. 1 are 527, 909, 2,488, and 1,050 , respectively.

Figure 1. Trends in Median Weekday Housework Time Reported by Married Women ${ }^{\mathrm{a}}$ 
Table 2. Weighted Tobit Parameter Estimates for the Equations Estimating Time Spent in Moderate PA Housework by Married Women

\begin{tabular}{|l|c|c|c|c|c|c|}
\hline Independent Variables & \multicolumn{3}{|c|}{1985} & & \multicolumn{2}{c|}{2017} \\
\hline & Means & Coefficient & t-Statistic & Means & Coefficient & t-Statistic \\
\hline Intercept & & 81.24 & $(9.17)^{* *}$ & & 48.50 & $(4.50)^{* *}$ \\
\hline Age $>\mathbf{4 0}(\mathbf{1}=$ yes, 0=no) & 0.46 & 10.26 & $(1.39)$ & 0.61 & 8.70 & $(1.08)$ \\
\hline$>\mathbf{1 2}$ Yrs of Education (1=yes, 0=no) & 0.37 & -1.81 & $(-0.26)$ & 0.68 & -14.59 & $(-1.88)^{*}$ \\
\hline Employment Status (1=yes, 0=no) & 0.63 & -59.01 & $(-8.37)^{* *}$ & 0.68 & -56.21 & $(-7.33)^{* *}$ \\
\hline Children < 18 (1=yes, 0=no) & 0.52 & 10.45 & $(1.43)$ & 0.49 & -16.80 & $(-2.13)^{* *}$ \\
\hline Weekend Diary Day (1=yes, 0=no) & 0.29 & 18.58 & $(2.48)^{* *}$ & 0.29 & 14.97 & $(1.90)^{*}$ \\
\hline Sigma & & 116.17 & $(41.92)^{* *}$ & & 149.16 & $(43.99)^{* *}$ \\
\hline
\end{tabular}

${ }^{*} \mathrm{p}<.10 * * \mathrm{p}<.05$.

Focus now on the 1985 to 2017 time period when married women's moderate PA housework falls below recommended levels of PA. Over this 32 year period, changes in socio-demographics could have altered the household's demand/need for such housework. Table 2 contains the mean socio-demographics for the 1985 and 2017 samples along with the weighted tobit parameter estimates for the moderate PA housework equations using both weekday and weekend day observations. The descriptive statistics suggest that the average married woman grew older, had more education, and was moderately more likely to be employed in 2017 compared to 1985 . The regressions reveal that paid employment is inversely related to moderate PA housework time across both surveys. In addition, women whose diaries are from weekend days report spending significantly more time in moderate PA housework than their otherwise similar counterparts with a weekday diary in both years. Having post-high school education is inversely linked to moderate PA housework time in 2017 but not in 1985 . Finally, the presence of minor children is associated with less time being spent in moderate PA housework in 2017 but not in 1985.

To assess what fraction of the decline in moderate PA housework is associated with the socio-demographic changes in the samples and what fraction is attributable to unmeasured changes in household technology, market alternatives, and/or cultural norms, an Oaxaca-Blinder decomposition is undertaken. The decomposition generates two sets of estimates depending on which set of coefficients are used as the starting point. These estimates serve as the lower and upper bounds of the percentage change attributable to shifts in sample characteristics and shifts in unmeasured factors (e.g., shifts in technological, market and/or cultural factors).

The mean decline in moderate PA housework time for women between 1985 and 2017 is about 23 minutes per day. When the 1985 estimates are used as the base, the decomposition suggests that $1 \%(<1$ minute $)$ of that decline in moderate PA housework time is attributable to socio-demographic changes in the samples, while $99 \%$ (22 minutes) is attributable to changes in unmeasured factors. In contrast, when 2017 estimates are the base for the decomposition, the figures are $13 \%$ ( 3 minutes) and $87 \%$ (20 minutes), respectively. These estimates suggest that somewhere between $1 \%$ and $13 \%$ of the decline in moderate PA housework is attributable to changes in socio-demographic characteristics of the samples.

\section{Discussion}

Earlier work by Church et al. [2] suggests that occupational shifts over the past 50 years have contributed to declines in PA and increases in obesity risk. Their work, however, did not include housework as an occupation. Similarly, Brownson et al. [1] note that women's time spent in household activities globally, has declined, and that this has likely contributed to the increase in the amount of time that American adults are inactive, but they did not look at changes in housework that involves moderate PA. The work presented here addresses this gap.

The current research suggests that while American married women's total time spent in housework has declined over the past $80+$ years, time spent in those housework activities that involve moderate PA has declined at a relatively faster rate. It also appears that only a modest amount of the relatively greater decline in moderate PA housework time is attributable to sociodemographic changes. The larger proportion of the overall change between 1985 and 2017 appears to be a function of shifts in unmeasured market forces (e.g., technological change, the fact that purchased household services became relatively cheaper) and cultural norms that were not captured by the more recent national surveys.

Perhaps the most important insights come from the descriptive information on trends. The descriptive information suggests that the average married woman living on a farm in Upstate New York in the 1930s exceeded the CDC's PA recommendations simply by doing her daily housework tasks. This was also true for the typical woman in the 1952, 1965-66, 1975-76, and 1985 surveys, although there was a downward trend in moderate PA housework time over this era. By 2003, however, the average time spent in moderate PA housework had declined below the CDC's recommendations. Thus, married women's growing energy imbalance may be attributable, in part, to the decline in moderate PA housework.

As with all studies, it is important to acknowledge the limitations of the current work so as to contextualize the conclusions that might be drawn. First, five of the seven surveys used in this study had different sampling strategies, data collection modes, and/or survey instruments. As a consequence, some differences in estimates across the surveys may reflect differences in design effects. Second, because the housework time-use categories are fairly broad and because the METs linked to these categories are 
averages, there could be some random estimation error in the measure of time spent in housework that generates 3.0+ METs [22]. Third, the linkage of METs estimates to time use categories was done in 2008. Since then, new household technologies could have further reduced the METs requirements for activities such as gardening and general housekeeping, thus leading to overestimation of moderate PA housework in the 2017 survey. Fourth, the omission of activities that required moderate PA in the early surveys but not in the later surveys (e.g., hanging clothes to dry) likely make estimates of the decline in moderate PA housework conservative. Finally, the percentage of women who are married in the U.S. has declined over the period covered by these surveys [28]. To the extent that non-married women spend less time in housework than married women, the current analysis likely underestimates the decline in moderate PA housework time for all women.

\section{Conclusion}

Historically, married women were likely to meet public health recommendations for PA through daily housework. In recent years, time spent in moderate PA housework has declined at a faster pace than housework time overall. The downward trend in moderate PA housework appears to be driven primarily by changes other than shifting socio-demographics. The introduction of labor saving household technologies and the expanded use of relatively cheap purchased services may have contributed to the downward trend. As a consequence, married women today may be less likely to achieve public health recommendations for PA than were their counterparts who lived in earlier times.

\section{Acknowledgments}

The research reported here was supported by a University of Utah Research and Creative grant. The author is appreciative of the feedback received when an earlier version of this work was presented at the 2018 Social Science History Conference.

\section{Statement of Competing Interests}

The author has no competing interests.

\section{References}

[1] Brownson, R.C., Boehmer, T.K., Luke, D.A. "Declining rates of physical activity in the United States: what are the contributors?" Annual Review of Public Health, 26. 421-43. 2005.

[2] Church, T.S., Thomas, D.M., Tudor-Locke, C, et al. "Trends over 5 decades in U.S. occupation-related physical activity and their associations with obesity" Plos One, 6 (5). e19657-e57. 2011.

[3] An, R., Xiang, X., Yang, Y., Yan, H. "Mapping the Prevalence of Physical Inactivity in U.S. States, 1984-2015," Plos One, 11 (12). e0168175-e75. 2016.

[4] Biswas, A., Oh, P.I., Faulkner, G.E., et al. "Sedentary time and its association with risk for disease incidence, mortality, and hospitalization in adults: a systematic review and meta-analysis," Annals of Internal Medicine, 162 (2). 123-32. 2015.

[5] Fishman, E.I., Steeves, J.A., Zipunnikov, V., et al. "Association between objectively measured physical activity and mortality in NHANES," Medicine and Science in Sports and Exercise, 48 (7). 1303. 2016

[6] O'donovan, G., Lee I.M., Hamer M., Stamatakis E. "Association of "weekend warrior" and other leisure time physical activity patterns with risks for all-cause, cardiovascular disease, and cancer mortality," JAMA Internal Medicine, 177 (3). 335-42. 2017.

[7] Carlson, S.A., Densmore, D., Fulton, J.E., Yore, M.M., Kohl, H.W., 3rd. "Differences in physical activity prevalence and trends from 3 U.S. surveillance systems: NHIS, NHANES, and BRFSS," Journal of Physical Activity \& Health, 6 Suppl 1. S18-S27. 2009.

[8] Ramey, V.A. "Time spent in home production in the twentiethcentury United States: new estimates from old data," The Journal of Economic History, 69 (01). 1-47. 2009.

[9] Bureau of Labor Statistics. Average Minutes per Day Men and Women Spent in Household Activities. Secondary Average Minutes per Day Men and Women Spent in Household Activities 2016. https://www.bls.gov/tus/charts/household.htm.

[10] Gershuny, J., Harms, T.A. "Housework now takes much less time: 85 years of US rural women's time use," Social Forces, 95 (2). 503-524. 2016.

[11] Vanek, J. "Time spent in housework," Scientific American, 231 (5). 116-21. 1974.

[12] Jann, B. "The Blinder-Oaxaca decomposition for linear regression models," The Stata Journal, 8(4). 453-79. 2008.

[13] Warren, J. Use of Time in its Relation to Home Management. Ithaca, NY: Cornell University Agricultural Experiment Station, 1940.

[14] Wiegand, E. Use Of Time By Full-Time And Part-Time Homemaker In Relation To Home Management. Cornell University, 1954.

[15] Converse, P.E., Robinson, J.P. Americans' Use of Time, 19651966, Inter-university Consortium for Political and Social Research, 1992.

[16] Juster, F.T., Courant, P.N., Duncan, GJ, Robinson, JP, Stafford, FP. Time Use in Economic and Social Accounts, 1975-1976, Inter-university Consortium for Political and Social Research [distributor], 1992.

[17] Robinson, J. Americans' Use of Time, 1985, Inter-university Consortium for Political and Social Research [distributor], 1997.

[18] U.S. Department of Labor. BLS. American Time Use Survey, 2003-2015 [United States], Inter-university Consortium for Political and Social Research [distributor], 2016.

[19] Robinson, J., Godbey, G. Time for life: The surprising ways Americans use their time: Penn State Press, 2010.

[20] Ainsworth, B.E., Haskell, W.L., Leon, A.S., et al. "Compendium of physical activities: classification of energy costs of human physical activities," Medicine and Science in Sports and Exercise, 25 (1). 71-80. 1993.

[21] Ainsworth, B.E., Haskell, W.L., Whitt, M.C., et al. "Compendium of physical activities: an update of activity codes and MET intensities," Medicine and Science in Sports and Exercise, 32 (9; SUPP/1). S498-S504. 2000.

[22] Tudor-Locke, C., Washington, T.L., Ainsworth, B.E., Troiano R.P. "Linking the American Time Use Survey (ATUS) and the compendium of physical activities: methods and rationale," Journal of Physical Activity and Health, 6 (3). 347-53. 2009.

[23] Centers for Disease Control and Prevention. Physical Activity Guidelines. Secondary Physical Activity Guidelines, 2018. https://www.cdc.gov/cancer/dcpc/prevention/policies_practices/ph ysical_activity/guidelines.htm.

[24] Bauer, T.K., Sinning, M. "Blinder-Oaxaca decomposition for Tobit models," Journal of Applied Economics, 42 (12). 1569-75. 2010.

[25] Sinning, M, Hahn, M., Bauer, T.K. "The Blinder-Oaxaca decomposition for nonlinear regression models," The Stata Journal, 8 (4). 480-92. 2008.

[26] Bryant, W.K. "A Comparison of the Household Work of Married Females: The Mid - 1920s and the Late 1960s," Family and Consumer Sciences Research Journal, 24 (4). 358-84. 1996.

[27] Wilson, M. The Use of Time by Oregon Homa Makers. Corvallis, OR: Agricultural Experiment Stations, Oregon State University, 1929. 
[28] U.S. Census Bureau. Historical Marital Status Tables: Figure MS-1b. Women's Marital Status. Secondary Historical Marital Status Tables: Figure MS-1b. Women's Marital Status, 2017. https://www.census.gov/data/tables/timeseries/demo/families/marital.html.

(C) The Author(s) 2019. This article is an open access article distributed under the terms and conditions of the Creative Commons Attribution (CC BY) license (http://creativecommons.org/licenses/by/4.0/). 